\title{
Natural Aging Effects on the Solutionizing Heat Treatment Process of the A6060 Al Alloy As-Cast Billets for Profile Production
}

\author{
Georgios K. Triantafyllidis, Natalyia V. Pukhalska, Dimitrios I. Zagkliveris \\ Department of Chemical Engineering, Aristotle University, Thessaloniki, Greece \\ Email: gktrian@auth.gr
}

Received 2 January 2015; accepted 21 January 2015; published 23 January 2015

Copyright (C) 2015 by authors and Scientific Research Publishing Inc.

This work is licensed under the Creative Commons Attribution International License (CC BY). http://creativecommons.org/licenses/by/4.0/

(c) (i) Open Access

\section{Abstract}

Recently results were presented for an $\mathrm{R} \& \mathrm{D}$ program for handling the as-cast billets of an $\mathrm{Al}-\mathrm{Si}$-Mg $\mathrm{A} 6060 \mathrm{Al}$ alloy at the solutionizing heat treatment temperature. A reduction in the solutionizing temperature of the as-cast billets from $585^{\circ} \mathrm{C}$ to $540^{\circ} \mathrm{C}$ was found. This leads to substantial energy savings without lowering the quality of the final commercial Al profiles. The alloy was treated from the microstructural point of view as an Aluminum Metal-Matrix Composite (Al-MMC). Strengthening of the Al matrix grains during the process was quantified and measured by micro-Vickers hardness testing. A possible application of this is to apply the suggested lower temperature solutionizing process to billets stockpiled in the factory for some months. The alloy undergoes natural aging, a physical process at ambient temperature that alters its microstructural features. Does this aging affect the quality of the lower temperature solutionizing treated profiles? The effect of the natural aging by micro-Vickers hardness testing on some of the same samples of our original work stockpiled in our lab for 10 months was investigated. We applied, further, the Image-Pro Plus image processing software on them in an effort to collect microstructural data and compared them to values taken 10 months earlier. Also we tried an interconnection between the two experimental processes treating the alloy as an Al-MMC.

Keywords

A6060 Al Alloy, Solutionizing, Natural Aging, Image Processing

\section{Introduction}

In a recently published paper [1], we presented the results of an R \& D program for handling the as-cast billets

How to cite this paper: Triantafyllidis, G.K., Pukhalska, N.V. and Zagkliveris, D.I. (2015) Natural Aging Effects on the Solutionizing Heat Treatment Process of the A6060 Al Alloy As-Cast Billets for Profile Production. Materials Sciences and Applications, 6, 111-116. http://dx.doi.org/10.4236/msa.2015.62014 
of an Al-Si-Mg A6060 alloy at the solutionizing heat treatment temperature. According to the data presented, a reduction of the solutionizing temperature from $585^{\circ} \mathrm{C}$ to $540^{\circ} \mathrm{C}$ was possible leading to substantial energy savings of the process without lowering the quality of the final commercial Al profiles. The whole program was based on a sequence of production steps that took place in the factory within some days, less than two weeks, after melting the raw materials and casting it in billets (solutionizing heat treatment, reheating the billets at $500^{\circ} \mathrm{C}$ and extruding them to final profiles, aging the profiles to achieve the best mechanical properties).

A question that arose since then was the possibility to follow the suggested lower temperature solutionizing process to billets stockpiled in the factory for some months. This material undergoes natural aging within this period. Natural aging at ambient temperature is a very complicated physical process that alters the microstructural features of these alloys [2] [3]. Does this type of aging affect the quality of the lower temperature solutionizing treated profiles?

We treated the material of our original work as an Al-MMC. We measured in [1] the strengthening of the Al matrix grains by micro-Vickers hardness testing and extended this type of measurements by using the same original samples ( $\alpha=15 \mathrm{~mm}$ cubes). This was done after 10 months of stockpiling in the lab. Image-Pro Plus optical metallography was performed at the samples in the past. The results are presented now for obvious reasons of comparison with the same job performed at the same sample after 10 months of stockpiling. Both experimental processes treat the material as an Al-MMC and help in answering the question.

\section{Experimental Procedure}

The whole experimental procedure is presented in [1]. We focused on the samples solutionized at the temperature interval between $530^{\circ} \mathrm{C}$ and $580^{\circ} \mathrm{C}$ and then cooled in air-fan $\left(25^{\circ} \mathrm{C}\right)$ after 70 and 80 min holding time at the set point. This temperature interval is critical for any practical conclusion.

In Figure 1 the microstructure of a sample for metallographic observation under polarized light is presented (200×). The $\mathrm{Mg}_{2} \mathrm{Si}$ phase between the $\mathrm{Al}$ matrix grains is white colored. Dark-colored are the Al matrix grains.

\subsection{Hardness Testing}

Micro-Vickers hardness testing data on the Al-matrix grains of our initial work samples when cooled in air fan at $25^{\circ} \mathrm{C}$ are presented in Figure 2. In the same figure data of measurements on the same samples after 10 months of stockpiling in our lab at $25^{\circ} \mathrm{C}$ are presented.

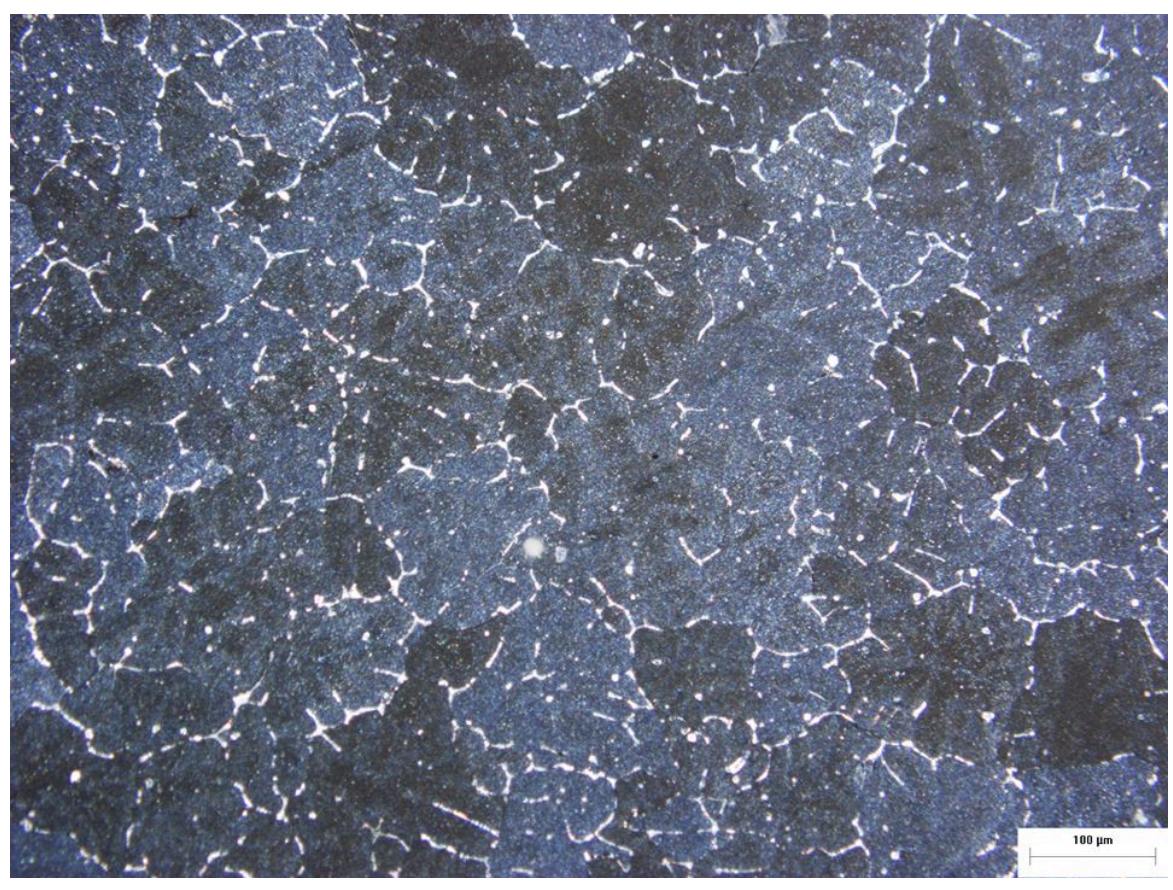

Figure 1. Microstructure of a sample for metallographic observation under polarized light. 


\subsection{The Image-Pro Plus Software}

We applied this program attached at an Olympus AX70 metallograph on properly prepared surfaces of the samples etched in Keller's reagent for metallographic observation. We collected microstructural data related to the $\mathrm{Mg}_{2} \mathrm{Si}$ phase that was solidified between the grains of the $\mathrm{Al}$ matrix (Figure 1). 10 photos for application of the Image-Pro Plus software for each temperature were taken. The numerical values referred are mean values of 10 measurements. In each measurement the program gives the following data regarding the underlined phase:

1. PER Area: Percentage of area occupation of the $\mathrm{Mg}_{2} \mathrm{Si}$ phase.

2. OBS: The number of objects of that phase per $\mathrm{mm}^{2}$.

3. Aspect Ratio: The ratio of the longitudinal to the transverse dimension of the $\mathrm{Mg}_{2} \mathrm{Si}$ grains.

The results are presented in Figures 3-8.

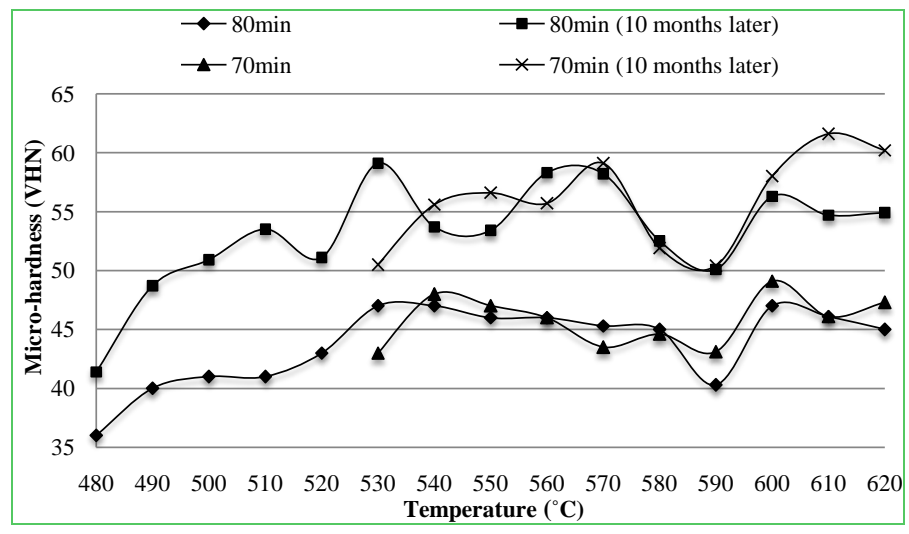

Figure 2. Micro-Vickers hardness testing data on the Al-matrix grains.

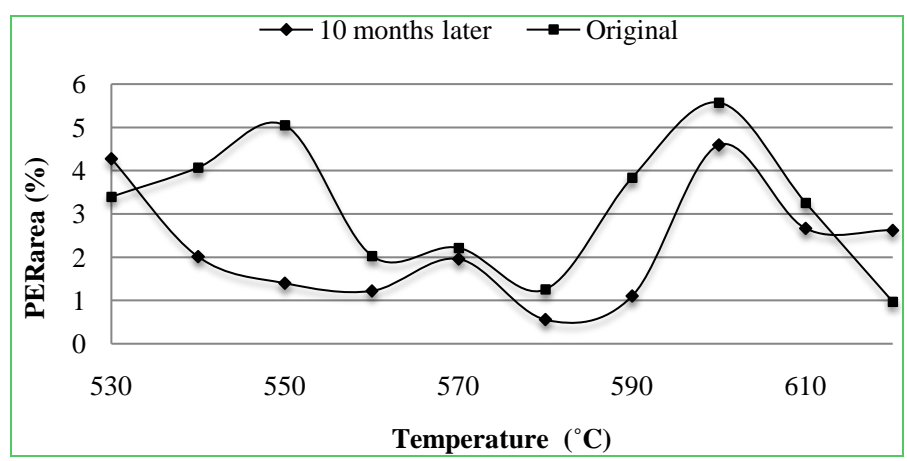

Figure 3. Image-Pro Plus data for PER area of samples solutionized for $70 \mathrm{~min}$.

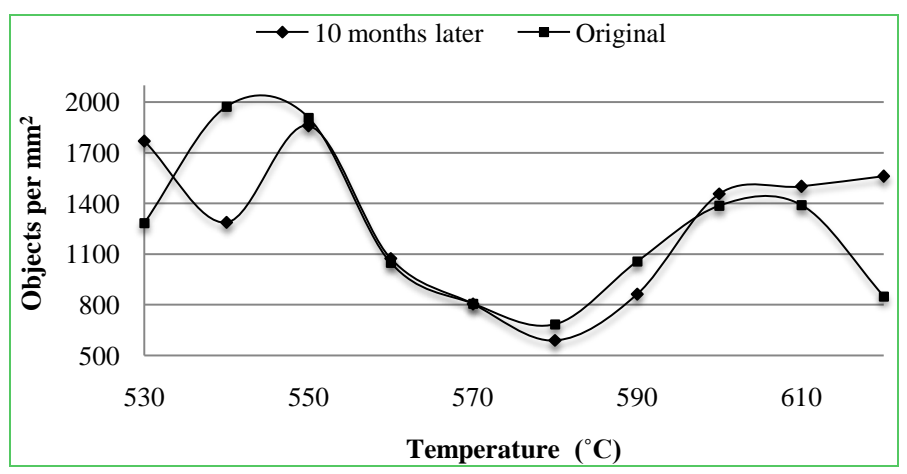

Figure 4. Image-Pro Plus data for number of objects of samples solutionized for $70 \mathrm{~min}$. 


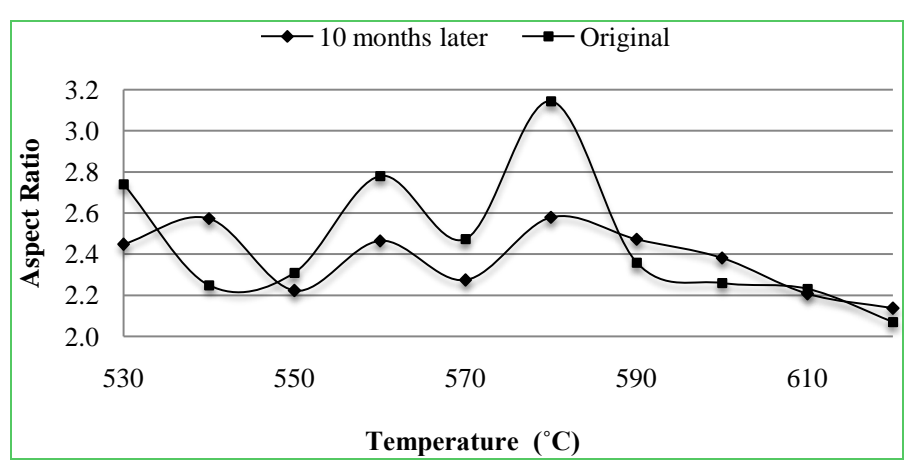

Figure 5. Image-Pro Plus data for aspect ratio of samples solutionized for $70 \mathrm{~min}$.

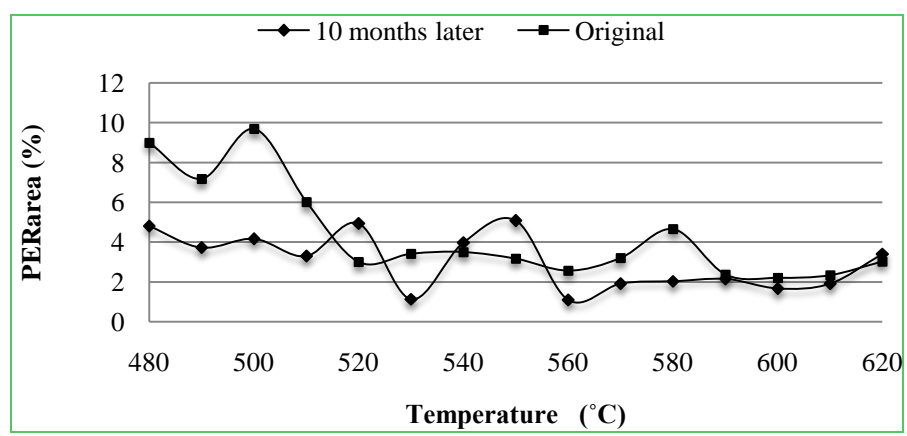

Figure 6. Image-Pro Plus data for PER area of samples solutionized for $80 \mathrm{~min}$.

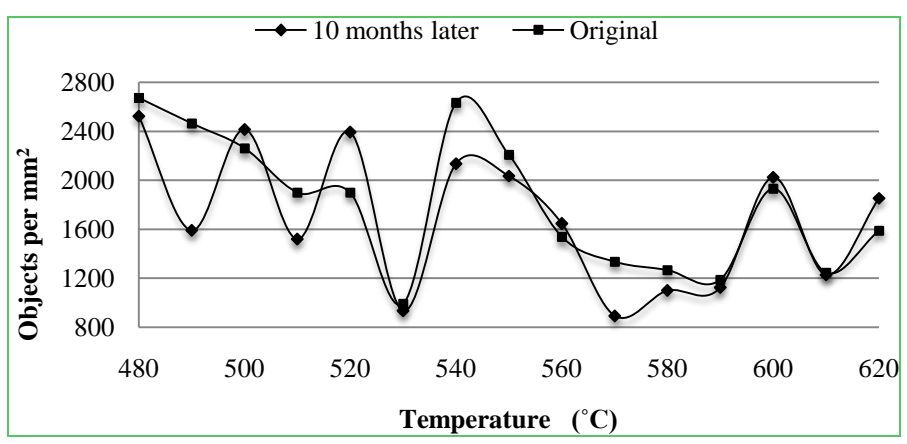

Figure 7. Image-Pro Plus data for number of objects of samples solutionized for $80 \mathrm{~min}$.

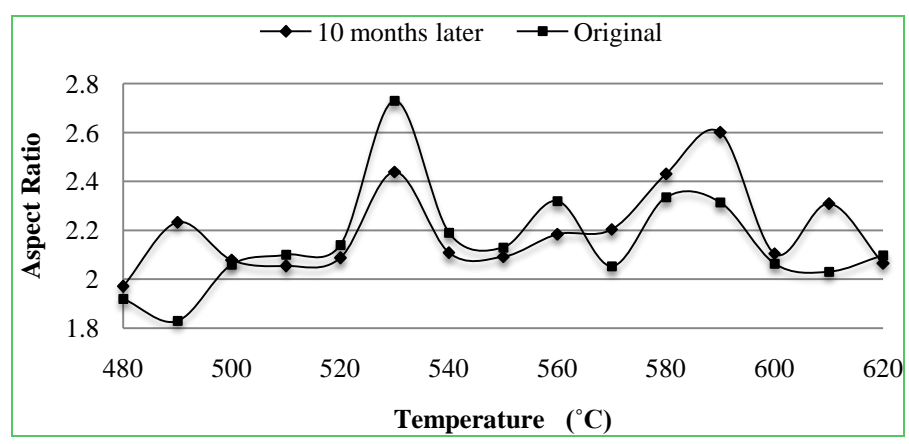

Figure 8. Image-Pro Plus data for aspect ratio of samples solutionized for $80 \mathrm{~min}$. 


\section{Discussion}

Both micro-Vickers testing and metallographic image processing indicate that diffusion controlled aging and atomic movement take place at room temperature:

1) The micro-Vickers profiles for both holding time conditions are shifted to higher values at about $20 \%$ for the whole temperature range. Values at levels more than 50 VHN are very close to those ones of the extruded material of the initial work [1]. This is very important observation for our conclusions. Micro-Vickers indentations occupy a very large area in comparison to the very small one of the objects of the Image-Pro Plus photographs.

2) In our initial work we found 25 VHN for the pure Al, 39 VHN for cubes of the as-cast billets, $45 \ldots 49$ with a min of 40 for cubes after solutionizing heat treatment and $54 \mathrm{VHN}$ for plates from these cubes as-extruded.

3) Now natural aging increases the VHN to $55 . .60$ with the minimum at 50 VHN (Figure 2). This is an increase at about $20 \%$ and is considered very high.

4) The Image-Pro Plus results indicate for the two out of three types of measurements (PER Area and number of objects per $\mathrm{mm}^{2}$ ) that the type of curves for each information varies seriously across the temperature range $530^{\circ} \mathrm{C}-580^{\circ} \mathrm{C}$ of the solutionizing experiments for both holding times (70,80 min) and timing of measurement (initial and after 10 months). The trend is to follow the micro-Vickers profiles.

5) A comparison of the two curves shows that they do not follow a specified way. This is attributed to the inherent drawback (bad statistics due to the small areas of measurements) of the method. They could be taken into consideration as an internal microstructural characteristic of the $\mathrm{Mg}_{2} \mathrm{Si}$ phase that has serious consequences on the strengthening of the $\mathrm{Al}$ matrix grains at ambient temperature:

- PER Area: It ranges from 4\% to 5\% to a minimum of 1\% for 70 min holding time for both measurements. More pronounced is the difference for 80 min holding (10\% to $1 \%$ ).

- Number of Objects: It ranges from 2000 to 600 . For holding time $70 \mathrm{~min}$ and for temperatures $520^{\circ} \mathrm{C}$ to $580^{\circ} \mathrm{C}$ is accomplished by a reduction of PER Area occupation values from $4 \%$ to $1 \%$. For 80 min holding time the number drops from 2700 to 600 with an abnormal behavior at about $540^{\circ} \mathrm{C}$ but PER Area is stabilized between $2 \%$ and $4 \%$.

- Aspect Ratio: Its value remains practically stable ranging between 2 and 3. This indicates the stable elongated nature of the $\mathrm{Mg}_{2} \mathrm{Si}$ islands between the Al matrix grains. They do not converge to a spherical shape.

\section{Conclusions}

The material is treated as an Al-MMC. The change in VHN values of the Al matrix grains after 10 months changes the conclusions referred in [1]. Diffusion controlled atomic movements in the Al matrix grains even at room temperature are responsible for the important strengthening.

These high strengthening values will alter the behavior of the material in an unpredictable manner in the subsequent processing steps (preheating for extrusion, extrusion, final aging). It is very difficult to be explained with the existing data.

The $\mathrm{Mg}_{2} \mathrm{Si}$ phase between the grains contributes substantially to strengthening effects of the Al matrix grains at ambient temperature. There exist modifications in its microstructural appearance as previously referred. These act as sources of strengthening.

The number of objects of this phase is reduced. This fact indicates transfer of $\mathrm{Mg}_{2} \mathrm{Si}$ material from the outside area of the grains to the $\mathrm{Al}$ grains at room temperature. After $580^{\circ} \mathrm{C}$ the reverse seems to happen.

This description alters significantly our plan described in [1] for recommending the lower temperature solutionizing process. Further research is necessary if industry wants to process billets stockpiled for months after solutionizing at the lower temperature cycle.

We do not recommend further processing of billets that were solutionized following the lower temperature cycle and stockpiled in the factory for months. This could be done only for the ones processed soon after casting and immediate solutionizing at lower temperature.

\section{References}

[1] Triantafyllidis, G.K., Kiligaridis, I., Zagkliveris, D.I., Orfanou, I., Spyridopoulou, S., Mitoudi-Vagourdi, E. and Semertzidou, S. (2015) Characterization of the A6060 Al Alloy Mainly by Using the Micro-Hardness Vickers Test in 
Order to Optimize the Industrial Solutionizing Conditions of the As-Cast Billets. Materials Sciences and Applications, 6.

[2] Banhart, J., Chang, C.S.T., Liang, Z., Wanderka, N., Lay, M.D.H. and Hill, A.J. (2010) Natural Aging in Al-Mg-Si Alloys-A Process of Unexpected Complexity. Advanced Energy Materials, 12, 559-571. http://dx.doi.org/10.1002/adem.201000041

[3] Banhart, J., Lay, M.D.H., Chang, C.S.T. and Hill, A.J. (2011) Kinetics of Natural Aging in Al-Mg-Si Alloys Studied by Positron Annihilation Lifetime Spectroscopy. Physical Review B, 83, Article ID: 014101. http://dx.doi.org/10.1103/PhysRevB.83.014101 
Scientific Research Publishing (SCIRP) is one of the largest Open Access journal publishers. It is currently publishing more than 200 open access, online, peer-reviewed journals covering a wide range of academic disciplines. SCIRP serves the worldwide academic communities and contributes to the progress and application of science with its publication.

Other selected journals from SCIRP are listed as below. Submit your manuscript to us via either submit@scirp.org or Online Submission Portal.
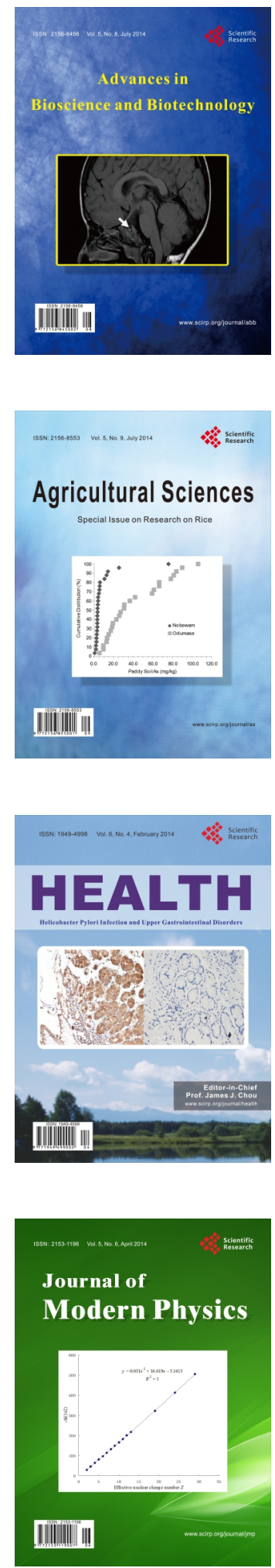
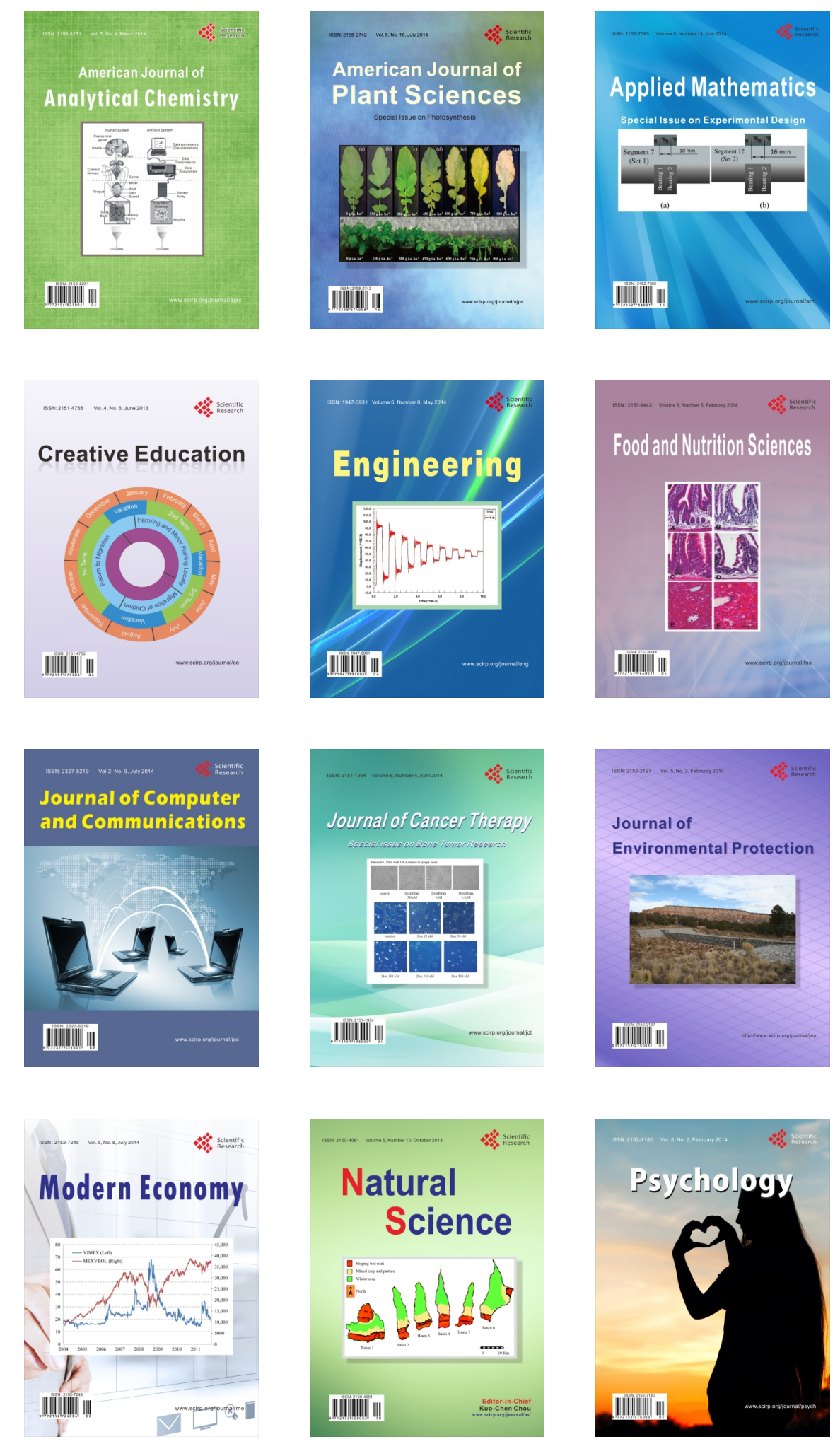